\title{
Studying the Implications of applying Gamification Technique on Knowledge Management in Projects
}

\author{
Harshal Charhate \\ Department of Computer Science and Engineering \\ SGSITS, Indore
}

\begin{abstract}
This conceptual research paper finds out if the application of gamification in the knowledge management can be considered as a positive factor in the project environment. The paper aims to examine the key relationships between gamification, knowledge management and human resource in projects. Primary findings in the result show that gamification brings significant improvement to the employee morale and performance, knowledge management practices and productivity of the project. The project managers, knowledge managers and human resource managers can seek to gain benefits from developing or utilizing tools based on gamified knowledge systems in the projects.
\end{abstract}

Keywords - Gamification, Game thinking, Knowledge management in projects, Project management.

\section{INTRODUCTION}

Knowledge and Knowledge management - Knowledge is recognized as a valuable and strategic resource for the organizations, which provides the organization with opportunities for growth and ability to gain competitive advantage. (Miller and Shamsie, 1996; Penrose, 1959; Winter 1987 cited in Wasko and Faraz, 2000). Knowledge management deals with the handling of this knowledge. In an organization, the management activities related to the way knowledge is created, acquired, represented, transferred and applied is defined as knowledge management. (Moshari 2013) The modern organizations have started to utilize computer-based information systems to manage knowledge in the projects. This change in the handling of knowledge has divided the management of knowledge into two distinct forms. One form treats the knowledge as an object that is created by people and it is stored in the databases for retrieval later. The other form treats knowledge as experience gained by the people which cannot be transformed into digital information. (Wasko and Faraz, 2000)

The knowledge management systems are deemed to be successful for the organizations if they can provide employees' the capability to easily obtain knowledge from it and also that the knowledge resources stored in them generate additional value. (Moshari 2013) In the overall organizational point of view the prominent issues in the knowledge management systems are related to globalization issues, issues based on knowledge economy and issues related to the growth of information and communication technology.

Knowledge practices in the projects can be described as the set of actions undertaken to transfer and share the knowledge within and between the information technology teams, business teams, and governance teams. (Reich et al 2013) The knowledge system in projects will then be described as a collection of knowledge stock, enabling environment and knowledge practices. (Reich et al 2012) The enabling environment is described as the technological and social conditions surrounding the knowledge stock.

Gamification - In its core is based on the simple concept of using game thinking, and emulating the elements of the game in various business/ non-game contexts. (Deterding et al 2011) The important property of game thinking that applies to gamification is objective oriented fun, instead of fun based on random play. It means that gamification requires developing of clear and defined objectives for all the tasks while maintaining partially the fun component that can be attached to each of the objectives. Another property of game thinking is the medium and low level of gameplay when compared to true games. This is a theoretical difference created as the gameplay in gamification is not supposed to be completely absorptive.

The work of Deterding et al (2011) in this area treats the gamification to be the utilization of design elements and characteristics of the game in other contexts. Accordingly, the gamification is treated not as an extension of the 
game or full game but consider as utilization of few related practices derived from the game's elements and characteristics. In the context of this paper, a more appropriate definition has been given by Dominguez et al (2013), which defines gamification as a concept incorporating game elements into a non-gaming application with an aim of enhancing the user experience and increasing the engagement. This definition is important as most of the modern gamification is application oriented, and thus tries to digitally engage with the users instead of personally engaging with them. (Dale, 2014)

Components of gamification - The game based interactions between the user and the gamified system are defined as the sum of game mechanics and game dynamics. (Dorling and McCaffery, 2012). The game mechanics broadly consists of factors like the achievements, exercises, community collaboration, transparent results, time keeping and luck. (Dale, 2014 and Kim, 2015). The sense of achievement is provided by use of points, levels or bonuses to incentivize actions of the users. Exercises take the form of challenges or quests given to the users or the discoveries required to be made by users, which can be used to make desirable behavior changes in the users. Community collaboration takes place in case of team play and with the use of leaderboards, which results in increasing the number of interactions. The real time results are in incorporated in the form of experience bars, continuous feedback or notifications what would keep the users connected to the system and still allow a sense of achievement. The time components like countdowns, speed checks and schedules are done to improve the efficiency of the users. Luck component like the lottery, random achievements, rewards or bonuses is again done to maintain the interest of users.

Game dynamics, on the other hand, considers the behavior, feedback and progression aspects of the gamification. (Kim, 2015) The behavior is represented in the desired changes in behavior needed, which are also used to develop the desired skills in the users. The feedback mechanism is used to control the direction of the change and to reiterate the knowledge of the known skills. Progression is used to stretch the skill level and allow for the accumulation of more meaningful skills.

Implementation - According to Kim (2015), the first step to implementing the design is to create clear goals. This is necessary as it provides information related to the expected outcomes and can be used to facilitate improvement later. The second step is to recognize the target audience and try to understand the characteristics of the users. (Kim, 2015and Dale, 2014) One such way is suggested by Bartle (1996), who speaks about the four distinct user types based on their motivation factors, i.e. achievers, explorers, socializers, and killers. The third step is to recognize the behavior that needs to be modified and the factors that can motivate the users to make those changes. (Dale, 2014) It is considered better to develop measures that can determine the success of the implementation. If such measures are developed then it will be regarded as the fourth step, which is optional.

Performance - Dale (2014) has summarized that the goals of most gamified systems developed are simply to motivate people. This is done with the aim that the employee and customer engagement will be improved, collaboration in the team will be more effective and innovation will be ratified. The use of gamified systems is also known to develop a productive and healthy environment for the employees in any industry. This aids the organizations in retaining the talent for longer periods and even attracting new employees. (Oprescu et al 2014).

The research objectives have been developed and designed based on the 'What', 'Why' and 'How' framework for management research. (Watson 1994) The framework was used to develop the research questions that corresponded to the purpose of the paper which is to find the implications of gamification on the knowledge management in projects. The researchable questions were shortlisted based on the priority to maintain a limited and bounded scope. The research objectives were developed in a way to broadly cover all the research questions. The following are the research objectives of this paper.

- Assess the important properties of the knowledge management practices in projects

- Identify the ways in which gamification technique can be applied to knowledge management

- Identify the generalized benefits of application of gamification technique.

- Develop a formal hypothesis based on the implications of using gamification technique on the knowledge management systems.

- Develop a formal hypothesis based on the impacts of using gamification technique on the projects and project environment. 
The initial three research objectives are attained by performing a simple review of the academic literature. This is attributed to a large amount of literature available to study the concepts in detail and understand the relationships highlighted in these objectives. On the other hand, the latter objectives will require a formal hypothesis to be developed, which will have to be based on an extensive and systematic review (Bryman and Bell, 2015) of the literature. This requires searching, listing and surveying the entire relevant literature base. The systematic review has to be performed by searching all the recognized journals and databases for relevant papers. A process modified and highly influenced from PRISMA developed by Moher et al. (2009) has been followed to develop the research plan for gathering and shortlisting the research material for analysis. The screened material undergoes content and context analysis to determine its usability and reporting is used as a tool to gather initial evidence for verifying the hypothesis. The resulting theory is treated as a result of the systematic review and used to aid in discussing the implications of the hypothesis.

Although different research approaches can be applied to achieve the given research objectives. Yet there is a lack of valid research assessing or measuring the impact of gamification statistically, and so the benefits can only be hypothesized theoretically rather than verified empirically. (Kim, 2015) The results of the paper are reduced to postulating and formulating of the simple hypothesis that has been derived from the final analysis. These hypotheses would aid in initiating the development of future research frameworks.

The rest of the paper is organized as follows. Literature Review is done in Section I. Research Design and process are explained in section III. The results are presented in section IV. Concluding remarks are given in section V.

\section{LITERATURE REVIEW}

The literature review begins by developing an understanding of the literature related to knowledge management in projects and establishing a status quo based on the relevant research. This is done by accessing the way knowledge management practices are applied in the projects and finding the key issues that are needed to be dealt with. The focus will then shift to finding the ways in which gamification can be applied to the knowledge management systems and how it will affect the systems. This requires surveying all the knowledge areas that can be influenced as well as develop a list of points to be considered while designing the gamified system. This would develop a clear understanding of the effect of gamified systems on the users and the knowledge system. Finally, the focus can be shifted onto the broader benefits that will be gained on the employees and stakeholders in the project. Key observations are also made during the literature review based on the research objectives established in the research.

Knowledge management practices in projects - According to Bhatt (2000), a knowledge management system composition contains $70 \%$ people while remaining $30 \%$ comes from process and technology. A primary issue about people in the knowledge management systems has been found to be the resistance of people in respect to sharing their knowledge (Hasan and Crawford, 2003). Thus for the long-term growth of the organization, it is necessary to gain commitment from all employees (Markus and Benjamin, 1997), as the increase in the involvement of employees in the projects will result in the success of the organization. (Kaufman, 1992)

Gilmour (2003) has shown that when proper focus is given to make employee bonding better, then the knowledge management is improved a lot more in comparison to the general systems where the focus is given more to capturing knowledge. When the people exchange their individual knowledge, then it will create more knowledge in the organization and when everyone participates in this exchange it also aids in increasing the individual learning from it. (Kogut and Zander, 1992; Nahapiet and Ghoshal, 1998, cited in Wasko and Faraz, 2000) The sharing and integration of such knowledge are dependent upon the development of information systems within the organization that would facilitate it. (Alavi and Leidner, 1999)

The key issues in knowledge management systems to consider when dealing with employees are the additional training needed by the employees, level of involvement of individual employees, the ability of the employees to work as a team and empowering of the employees to perform better. (Moshari, 2013) It should be remembered that the employees are often treated as a resource within the organizations during the projects. This happens as employees invariably can be considered as knowledge assets who are valued for their competencies, customer relationships, and innovations.

Observation 1: People form an important component of any knowledge management system in an organization and the success of such a system. 
The knowledge management systems can perform better, when the managers are deliberately trying to improve the performance, by incentivizing the dynamic interactions between the technology and people resulting in modifying the human behavior. (Gallivan et al 2002). A negative reaction could be achieved if the incentives developed are conflicting in nature.

Reich et al (2013) studied the effects of knowledge management on projects and showed that the levels of knowledge management are directly proportional to the project based knowledge and the knowledge alignment. Also, that the levels of knowledge alignment are directly proportional to the project performance. The project based knowledge in this study is defined as the sum of technical, organizational and business knowledge, while knowledge alignment refers to the level of congruence between the three types of knowledge. Project performance is regarded as the collection of the current and future benefits that would be gained from the system. (Globe et al 2008), while project management performance could be taken in various ways, one of the simplest is in terms of budget and schedule (Gemino et al 2008). It is important to know that the knowledge alignment does not have any significant negative impact on the project management performance as far as budget and schedule are concerned.

Observation 2: The project performance is dependent on the amount and quality of the knowledge in the knowledge management system during projects.

Gamification technique in knowledge management - Oprescu et al (2014) talk about the following 10 guiding principles, denoted as mnemonic IPLAYATWORK, for gamifying the system. He also describes the benefits to the users that will achieve by following each of them. These principles can be simplified and described as

- I-orientation which puts the employee at the center of the game. This can increase employee engagement and provides him a sense of control and self-sufficiency.

- Persuasive elements are designed to be able to persuade people to change. These can work well in new initiatives as well as increase the levels of employee satisfaction.

- Learning Orientation deals with skill development and gaining knowledge. It can be useful in developing personal capability and organizational resources.

- Achievement based rewards are ways to justify the employee actions and provide him with the return of investment. It can increase the level of employee satisfaction and retention rate of the organization.

- Y generation adaptable deals with the theory that $\mathrm{Y}$ generation will find it easier to adopt to the technology aspect. It can increase the employee acquisition and retention rates for the organization.

- Amusement is achieved due to the fun nature of the method. It can increase the levels of employee satisfaction and feeling of wellbeing.

- Transformative deals with the sense of competition and collaboration among the employees. It can impact the productivity of the employees which in turn would increase the productivity of the organization.

- Wellbeing oriented nature focuses the method on concentrating on the employee wellbeing. This enhances the feeling of wellbeing in the employees.

- Research Generation is an additional advantage of the method for the future due to the present increase in collaboration. This can enhance the monitoring and decision making among the employees.

- Knowledge-based would require it to provide feedback and details of the outcome. This can help in developing individual capabilities and organizational resources.

One of the areas that gamification is applied is the systemization of the knowledge management in projects. (Davidson and Rowe, 2009) The task of the gamified system would be to encourage or motivate the people to aid in the knowledge capturing and storage during the project milestones or review points. If people begin to perform these actions, then the study indicates that the knowledge generated in the project will be improved as well and it can also lead to personal and organizational learning. Gamification is also being already used as an agent to help bring in business change that can result in improvement of business. (Dale, 2014)

There is huge prospect visible of applying gamification that can provide a lot of benefits to the projects and the project environment. When it is applied to the knowledge management system to increase the knowledge sharing by the employees, the project environment automatically will become more conducive to give better business value, as 
the employees will begin to show increased trust among each other and willingness to share their knowledge. (Quigley et al, 2007) This practice of increased sharing among the employees also reflects the positive impact on the project performances. (Faraz and Sproull 2000). The increase in sharing of knowledge will increase the amount of knowledge stocked by the employees in the system, is will result in better value generation. (He et al, 2007).

Observation 3: Motivating the employees is highly beneficial to the knowledge management system and in turn project performance.

Project managers will play an important part in making any system successful. Project managers are responsible for developing the knowledge practices and methods for knowledge sharing. These practices would have a significant impact on the quality of the knowledge created by the project team. (Reich et al, 2012) The project manager also has to deal with the issues related to leadership, commitment and support in a knowledge management system. (Moshari, 2013) The way the project managers manage the knowledge in the knowledge-intensive projects can result in improving the business value achieved from those projects a lot. (Reich et al 2012)

If the project managers spent the time to understand the factors influencing the behavior of their team, then they can use gamification to encourage specific attributes in the project team. (Dale, 2014) They can also use it align the project goals with the individual goals of each member thus enabling them to achieve better. There is also the additional benefit that the business processes become more enjoyable for the team members.

Observation 4: The decisions made by project managers about knowledge management systems have a significant effect on the outcomes of the projects.

Benefits of Gamification - Gamification practices have been widely successful to increase the level of interest among the people using the systems. The first beneficial impact which is seen directly is the increase in the number of user interactions and the increase in user engagement to the system. (Deterding et al 2011) According to the same study, this increase will also benefit the problem solving in key areas including, the time during the projects. The property of increase of user engagement by motivation is also used to increase the user involvement in the needed activities. (Hamari, 2013) This motivation can be explained as a property of gamification to act as a social motivator by impacting the social skills of the users directly and enabling them to have more interactions. (Hamari and Koivisto 2013). According to the study by Oprescu et al (2014), gamified systems are also useful in increasing the work satisfaction by resolving psychological issues related to the high-stress levels, loss of sense of community, reduced level of loyalty and changing environments. One of the key factors to remember when motivating by incentives in the gamification is to not use money as a motivation tool. (Dale 2014) This is because using extrinsic rewards like money will have a negative detrimental effect in the long term, on the intrinsic motivation factors of the users. (Kim 2015) It is also noted that in the case of short-term projects, this negative effect does not exist and external rewards are an important tool to increase the motivation rapidly.

The application for gamification seems to be successful when applied to a variety of domains and systems. This has been attributed to the high level of effectiveness (Hamari et al, 2014) and increase the productivity of the people who were using the gamified systems. (Mario 2014) There is also been a high level of acceptance among the user of the systems on which gamification has been applied. (Herzig et al 2012). This also tends to direct upon the fact that the gamified systems are ease to handle even after changes are made to the original system.

Observation 5: Gamification provides motivation to the users and aids in improving the productivity of the user working with the system.

\section{RESEARCH DESIGN}

The conceptual framework as seen in Figure 1 has been developed for conceptualizing the derived relationships and interactions among the components in the project environment. This conceptual framework can easily be correlated with the research objectives of the paper. The arrows are used to describe the nature of the dependencies and relevant relationships among these components. For example gamification system will have some direct implications on the knowledge management and the people involved in the projects, while knowledge management and people, in turn, are directly affecting the project. 


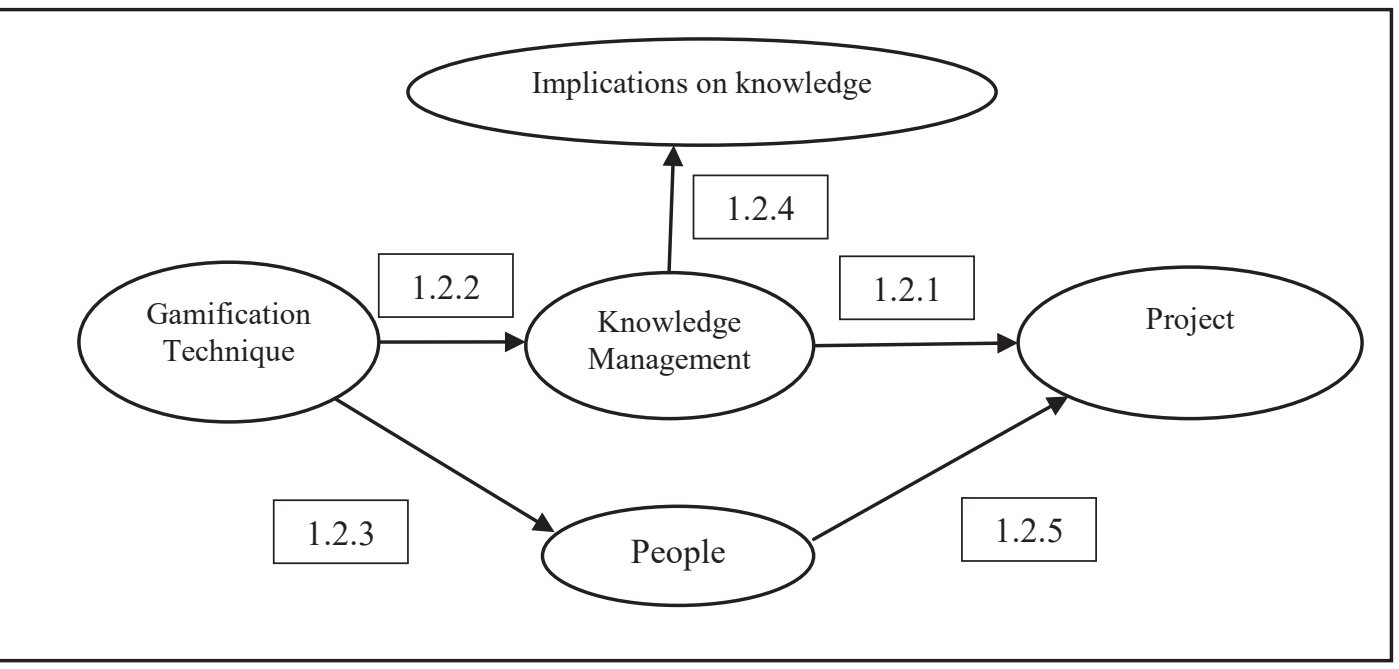

Figure 1 Conceptual framework of project environment based on similar concept referred from Miles and Huberman, 1994

The informal hypothesis has been developed from the conceptual framework and research objectives by making theoretical considerations about the cause and effect relationship between the components. The hypothesis is used to identify the relationships between gamified knowledge management system and the other components in the project environment.

\section{A) Research Process and Systematic Review}

Data Collection - The primary task for the selected research methodology and research process is to find theoretical evidence related to the hypothesis. Such evidence requires a replicable, extensive and exhaustive process which would search all the present research materials for the source, in a way better than traditional ways of the literature review. Thus the research process(Moher et al 2009, Bryman and Bell, 2015) shown in Figure 2 is utilized for gathering the evidence. The collection of data in this process is similar to a systematic review in many ways, one of them is that it performs an exhaustive search of the relevant literature in the published materials. This research process was also selected as it allowed for all the relevant academic journals and online databases to be searched while maintaining the ability to be easily duplicated in the future if the same sequence is followed.

The relevant articles are identified in the databases and journals by searching using keywords. To limit the number of articles targeted keywords were obtained from the literature review that could list all applicable resources. The primary keywords used for identification of relevant articles were gamification, game-thinking, game mechanics and gameful design.

The number of articles identified after the first step was high in number and not all articles were relevant to the research. The articles had to be reduced to before performing any useful analysis. The second step, there is a reduction in the number of articles based on their relevance. This could be done by creating a secondary set of keywords that would help screen the papers collected in the previous step. These secondary keywords were built from the topics under consideration in the project and after experimentation was done using similar terms to determine the best way to word them. The secondary keywords used were gamification application, knowledge management, project environment, project management and human resources. The combination of primary and secondary keywords allow the gathered articles to be a finite in number that could be analyzed by the review. 


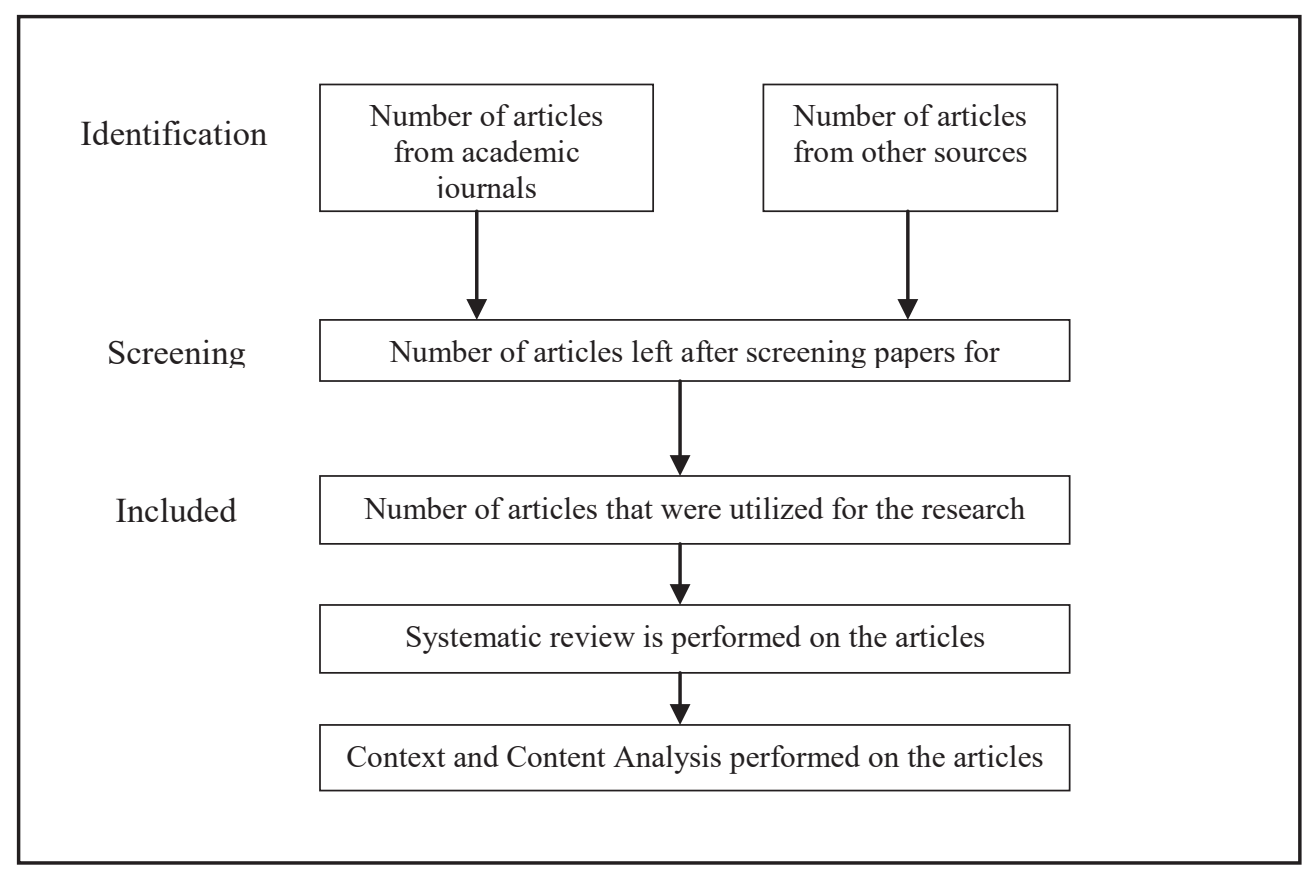

Figure 2 Flow Diagram for research process modified from Moher et al (2009)

The third step in the process is based on finding the relevant articles that could provide distinct and valuable perspective towards the discussion on the claims made in the hypothesis. These articles should be are able to provide support to the research. This step is also useful in declining the effects of outliers from affecting the research by removing the articles that have very little relevance and lack supporting evidence.

The systematic review is also a form of evidence-based approach, i.e. it aids in identifying and finding all the available evidence in the current literature. (Bryman and Bell 2015) The data collection steps used in the current research process corresponds to the systematic review. The needed evidence for discussions on the hypothesis is obtained by performing a content and context analysis based systematic review on the collected articles.

Content and Context Analysis - Content analysis is the analysis approach that quantifies the content in the articles, on the basis of a predetermined theme or subject, and conducts it in a systematic and replicable manner. (Bryman and Bell 2015) The content analysis is used to find a number of articles and areas that show the positive impact of gamifying systems or applying gamification in the processes and methods. These would help determine the positive nature of the approach and also identify articles that talk about any negative impact.

Context analysis is performed to neutralize the theoretical nature of the content analysis which laid more significance on the measures than on the theoretical significance of the subject. Context Analysis is useful on its own to determine the cause of the impact and not just the nature of it. The context analysis in this paper deals with the context in which gamification is employed, the environmental factors that influence it and also the factors influenced by gamification. It aids in explaining why something has occurred in the article or the way it is. It would be useful in finding the evidence for the hypothesis.

\section{EXPERIMENT AND RESULT}

Out of the 26 papers that underwent content analysis, 24 of them showed a positive response or effect from the use of gamification. Meanwhile only one of them talks about negative impact from the use of gamification. The negative impact, in that case, was attributed to the lack of support for the gamification process which led to its failure in completing all user requirements. The result of the content analysis clearly shows that the processes or areas where gamification has been applied in past generally shows a positive impact on those areas and the connected people.

H1: Gamification in the knowledge systems will positively impact the knowledge volume in the projects. 
The first hypothesis deals with the amount of knowledge stock and the quality of the knowledge and knowledge workers in a gamified knowledge system. Vasilescu et al (2014) can be used to show evidence by direct comparison how gamification had resulted in the increase of contributions to the knowledge in a community and along with increased interest in the knowledge sharing due to the use of gamified elements. Fernández-Luna et al (2014) have also shown in his research how gamification positively impacts the collaboration between all the users. The increase in collaboration is directly relevant to the improvement in the quality of knowledge gathered.

One of the topics touched in Roth et al (2015) is about the technology of crowdsourcing systems and how the use of gamification has resulted in massive participation for these systems. Cudney et al (2015) talk about the development of gamified knowledge management system in healthcare that was able to engage more users and drive traffic to towards the usage of the system. This increase in the user input and participation gives this system an advantage over other systems by making them more effective. Kingsley and Grabner-Hagner (2015) has also displayed how gamification allowed the consumers of knowledge to be converted into the producers of the information. This conversion develops the skills of users and they begin to get more involved by learning to communicate and collaborate better.

It can be observed from the evidence found that the gamification would result in the increase in the quantity of knowledge exchanged as well as the knowledge stored in the systems. This increase in the knowledge stock would have a positive impact on the project environment of knowledge-intensive projects, as it had lead to an increase in knowledge resource.

\section{H2: Gamification in the knowledge systems will positively impact the success and value of the project.}

This hypothesis deals with the aspects of gamified knowledge systems in relation to long term and short term benefits to the project and the degree of influence on the success of the project. Barata et al (2013) can be used as evidence as it had studied the impact of gamification on various performance measures by comparing the performance when gamification was not applied to the performance when gamification was applied. That study showed a significant positive development in the gamified system due to the increase in the active participation of the users. The study by Morrison and DeSalvo (2014) showed that even in a flawed gamification system implemented by Khan Academy, there was a positive growth in the benefits that user gained from the system.

According to Iosup and Epema (2014), the use of gamification in educational project initiatives resulted in an increase in the number of participants in the learning process, while also getting substantial success in the results of the tests based on those learning. As the improvement in the result was the desired benefit, it showed that gamification can bring required results. A contradictory study done by Heilbrunn et al (2014) showed that the lack of continued support in gamification projects results in failure to complete all the user requirements. It fortifies the point that during the initial period of the gamified systems there is the occurrence of various issues that have to be managed to be eventually successful. Richards et al (2014) clearly showed that by understanding the stakeholders' requirements and context, the problems that arise in the gamification systems can be detected early and can be removed by making relevant modification in the gamified system.

A great evidence is provided by Rodrigues et al (2013) about the success of applying gamification, as it deals with the application of gamification in the business context. The paper determined by experimentation that gamification had a positive impact on the e-business and customers. It was also found that the high customer participation had also brought high financial gains for the organization.

All this relevant evidence points to the fact the gamified knowledge system would increase the chances of getting success in the project and will also positively impact the business value of the projects. The gamified system provides the project with an increase in the positive activity level as people get trained better, and gain the relevant skills and capabilities, allowing them to perform the tasks better.

\section{H3: Gamification in the knowledge systems will positively impact the efficiency or performance of the employees.}

This hypothesis deals with the degree of influence and ramifications that gamified knowledge systems would have on its users. Evidence can be shown in the form of Cechonowicz et al (2013), who performed empirical research on the motivational effect of gamification in various areas and found that gamification does provide employees with motivation, and also that such motivational benefits increase with an increase in the level of gamification. Roth et al (2015) also illustrate how the gameplay applied to communication, has been impactful in using game design to stimulate creativity and innovation in the users. 
There is also evidence gained from actual gamified systems developed in the organizations. Kappen and Nacke (2013) discussed how the gamified system like Plantsville developed by Siemens and CityOne developed by IBM impacted their employees. It showed that the organizations were able to use gamification successfully to familiarize the employees with new concepts in case of Plantsville and address problems with the old systems in case of CityOne. Bowser et al (2013) also reiterate the same fact in his paper that gamification is able to attract new users while keeping the old users engaged. Blohm and Leimeister (2013) gave additional evidence when they discussed how the development of incentive system like Nikefuel by Nike resulted in providing the users motivation and elevating their satisfaction so that users were able to make changes in their behavior.

Hamari (2015) studied how the effect of the gamefulness reduced over time and diluted the effects of motivation gained from having fun. Another important conclusion was that the users are most motivated in such systems due to the sense of competition when compared to other game factors. Meckler et al (2013) on the other hand was able to find a positive relationship between a few basic game design elements and the performance of users. The research was able to confidently show that the use of these game elements did not have adverse effects on the users.

It can be observed from the supporting evidence that the performance of the employees is improved by gamified systems. Apart from the performance gains, there are also various psychological advantages gained by the employees while working in a gamified system. These gains act to reduce the risk of people leaving the project midway in the projects, due to psychological issues like stress or lack of satisfaction.

\section{V.CONCLUSION}

The hypothesis made to fulfill research objectives earlier in the paper seem to hold, in the face of the evidence found in favor of them. The gamification technique seems to provide a sense of positive reinforcement to the users in the desired direction that can be governed by the system developers. It was also observed during the research that when gamification was applied to a similar environment as in projects, it showed positive implications in both short term and long term for those environments. It is also definite that gamifying provides benefits in terms of increased productivity and improved work satisfaction for the employees working on those projects. Gamification also has been used to increase the motivation for the users. It can be utilized as a user engagement tool, to use when the employees are working on new and unfamiliar projects. It will also work as an effective way to manage the business changes.

Limitations - The overall research in gamification is limited as the field is still in the early stages of understanding. The limitation also lies in the fact that although gamification is a promising area, no research is yet available on the best practices or best ways of utilizing it during the projects. This leaves the research open to critique especially as the gamifying methods are still being improved and modified. Conclusive research in this area would allow the current research to have a more potential impact in the future.

Future research - The conceptualization did in this paper is not theoretically complete and further research is required to make any concrete construct. One of the key elements lacked during the research was the absence of practice-based research as no knowledge system was found that had gamification applied. Such findings were not possible due to the nonexistence of a knowledge management system based on gamification in the current organizations. Development of such a system would allow for direct experimentation and empirical research.

There is a lack of empirical research in this research area which could ascertain that the gamification in knowledge systems would indeed provide the said benefits. Performing such research would also allow the benefits to be quantified so that modifications to the game elements can be experimented upon.

\section{REFERENCES}

[1] Bhatt, D. (2000) "EFQM Excellence model and knowledge management implications", Published by EFQM Organization, 8.

[2] Barata, G., Gama, S., Jorge, J., and Gonçalves, D. (2013). Improving participation and learning with gamification. In Proceedings of the First International Conference on Gameful Design, Research, and Applications 10-17

[3] Bartle, R. (1996) "Hearts, Clubs, Diamonds, Spades: Players who suit MUDs", self-published, available: http://mud.co.uk/richard/hcds.htm

[4] Blohm, I., and Leimeister, J. M. (2013). "Design of IT-Based Enhancing Services for Motivational Support and Behavioral Change", Business and Information Systems Engineering

[5] Bryman, A. and Bell, E. (2015) Business research methods, Oxford university press

[6] Borges, S., Durelli, V. H., Reis, H. M., and Isotani, S. (2014). "A systematic mapping on gamification applied to education." Proceedings of the 29th Annual ACM Symposium on Applied Computing, 216-222

[7] Bowser, A., Hansen, D., He, Y., Boston, C., Reid, M., Gunnell, L., and Preece, J. (2013). Using gamification to inspire new citizen science volunteers. In Proceedings of the First International Conference on Gameful Design, Research, and Applications 18-25.

[8] Cechanowicz, J., Gutwin, C., Brownell, B., and Goodfellow, L. (2013). Effects of gamification on participation and data quality in a realworld market research domain. In Proceedings of the First International Conference on Gameful Design, Research, and Applications 58-65. 
[9] Cudney, E., Murray, S., Sprague, C., Byrd, L., Morris, F., Merwin, N. and Warner, D. (2015) "Engaging Healthcare Users through Gamification in Knowledge Sharing of Continuous Improvement in Healthcare", Procedia Manufacturing, 3, 3416-3423

[10] Dale, S. (2014) "Gamification: Making work fun, or making fun of work?" Business Information Review, 31(2), 82-90.

[11] Davidson, P. and Rowe, J (2009) "Systematising knowledge management in projects", International Journal of Managing Projects in Business, 2(4), $561-576$

[12] Deterding, S., Dixon, D., Khaled, R. and Nacke, L (2011) "From game design elements to gamefulness: Defining gamification", Proceedings of the 15th International Academic MindTrek Conference, 9-15.

[13] Domínguez, A., Saenz-de-Navarrete, J., De-Marcos, L., Fernández-Sanz, L., Pagés, C., and Martínez-Herráiz, J. (2013), “Gamifying learning experiences: Practical implications and outcomes", Computers and Education, 63, 380-392.

[14] Dorling, A., and McCaffery, F. (2012) "The gamification of SPICE”, Software Process Improvement and Capability dEtermination, 295301

[15] Faraj, S., and Sproull, L. (2000) "Coordinating expertise in software development teams", Management Science, 46(12), $1554-1568$.

[16] Fernández-Luna, J. M., Huete, J. F., Rodríguez-Avila, H., and Rodríguez-Cano, J. C. (2014). Enhancing collaborative search systems engagement through gamification. In Proceedings of the First International Workshop on Gamification for Information Retrieval 42-45.

[17] Gable, G., Sedera, D. and Chan, T. (2008) "Re-conceptualizing information system success: the IS-impact measurement model", Journal of the Association for Information Systems, 9(7), 377-408

[18] Gallivan, M. J., Eynon, J., and Rai, A. (2003) "The challenge of knowledge management systems: Analyzing the dynamic processes underlying performance improvement initiatives", Information Technology and People, 16(3), 326-352.

[19] Gemino, A., Reich, B. and Sauer, C. (2008) “A temporal model of information technology project performance", Journal of Management Information Systems, 24(3), 9-44

[20] Gilmour D. (2003) "How to fix Knowledge Management”, Harvard Business Review

[21] Hamari, J. (2015) "Why do people buy virtual goods? Attitude toward virtual good purchases versus game enjoyment" International Journal of Information Management, 35(3), 299-308.

[22] Hamari, J. (2013). "Transforming Homo Economicus into Homo Ludens: A Field Experiment on Gamification in a Utilitarian Peer-To-Peer Trading Service", Electronic Commerce Research and Applications, 12 (4), 236-245.

[23] Hamari, J., and Koivisto, J. (2015) "Why do people use gamification services?" International Journal of Information Management, 35(4), 419-431. doi:10.1016/j.ijinfomgt.2015.04.006

[24] Hamari, J., and Koivisto, J. (2013). "Social motivations to use gamification: an empirical study of gamifying exercise", Proceedings of the 21st European Conference on Information Systems, Utrecht Netherlands.

[25] Hamari, J., Koivisto, J., and Sarsa, H. (2014) "Does Gamification Work? - A Literature Review of Empirical Studies on Gamification", Proceedings of the 47th Hawaii International Conference on System Sciences, Hawaii USA.

[26] Hanisch, B., Lindner, F., Mueller, A. and Wald, A. (2009) "Knowledge management in project environments", Journal of knowledge management, 13(4), 148-160.

[27] Hasan, H., and Crawford, K. (2003). "Codifying or enabling: the challenge of knowledge management systems", Journal of the Operational Research Society, 54(2), 184-193.

[28] He, J., Butler, B. and King, W. (2007) "Team cognition: development and evolution in software project teams", Journal of Management Information Systems, 24(2), 261-292.

[29] Heilbrunn, B., Herzig, P., and Schill, A. (2014). Tools for Gamification Analytics: A Survey. In Utility and Cloud Computing (UCC), 2014 IEEE/ACM 7th International Conference on 603-608). IEEE.

[30] Helberger, N. (2011) "Diversity by design", Journal of Information Policy, 1, 441-469.

[31] Herzig, P., Strahringer, S. and Ameling, M. (2012). "Gamification of ERP Systems-Exploring Gamification Effects on User Acceptance Constructs", Multikonferenz Wirtschaftsinformatik, 793-804.

[32] Hew, K., Huang, B., Chu, K. and Chiu, D. (2015) "Engaging Asian students through game mechanics: Findings from two experiment studies", Computers and Education.

[33] Huotari, K., and Hamari, J. (2012). "Defining gamification: a service marketing perspective", Proceeding of the 16th International Academic MindTrek Conference, 17-22

[34] Iosup, A., and Epema, D. (2014). "An experience report on using gamification in technical higher education." In Proceedings of the 45th ACM technical symposium on Computer science education 27-32

[35] Kappen, D. L., and Nacke, L. E. (2013). The kaleidoscope of effective gamification: deconstructing gamification in business applications. In Proceedings of the First International Conference on Gameful Design, Research, and Applications 119-122.

[36] Kaufman, R. (1992). "Why operations improvement programs fail: Four managerial contradictions", Sloan Management Review, 21(3), 1720.

[37] Kim, B. (2015) “Designing Gamification in the Right Way”, Library Technology Reports, 51(2), 10-35.

[38] Kingsley, T., and Grabner-Hagen, M. (2015). "Gamification", Journal of Adolescent and Adult Literacy, 59(1), 51-61

[39] Maltzahn, C., Jhala, A., Mateas, M., and Whitehead, J. (2014). Gamification of private digital data archives management. In Proceedings of the First International Workshop on Gamification for Information Retrieval 33-37.

[40] Mario, H. (2014) Gamification in Human Resources, EGC Media.

[41] Markus, M. and Benjamin, R. (1997) "The magic bullet theory in IT-enabled transformation", SLOAN MANAGEMENT REVIEW, 38(2), 5568 .

[42] Mekler, E. D., Brühlmann, F., Opwis, K., and Tuch, A. N. (2013). "Do points, levels and leaderboards harm intrinsic motivation? an empirical analysis of common gamification elements." Proceedings of the First International Conference on Gameful Design, Research, and Applications 66-73.

[43] Miles, M.B., and Huberman, A.M. (1994) "Qualitative data analysis: An expanded sourcebook", Thousand Oaks: Sage

[44] Moher, D., Liberati, A., Tetzlaff, J., Altman, D.G. and The PRISMA Group (2009) "Preferred Reporting for Systematic Reviews and MetaAnalysis: The PRISMA statement", PLOS Med, 6(6)

[45] Morrison, B. B., and DiSalvo, B. (2014). Khan academy gamifies computer science. In Proceedings of the 45th ACM technical symposium on Computer science education 39-44.

[46] Moshari, J. (2013) "Knowledge Management Issues in Malaysian Organizations: The Perceptions of Leaders", Journal of Knowledge Management, 3(5), 15-27 
[47] Oprescu, F., Jones, C. and Katsikitis, M. (2014) "I PLAY AT WORK - ten principles for transforming work processes through gamification", FRONTIERS IN PSYCHOLOGY, 5(1), 14

[48] Pandey, S. C., and Dutta, A. (2013) "Role of knowledge infrastructure capabilities in knowledge management", Journal of knowledge management, 17(3), 435-453.

[49] Pedreira, O., García, F., Brisaboa, N., and Piattini, M. (2015). "Gamification in software engineering-A systematic mapping." Information and Software Technology, 57, 157-168.

[50] Quigley, N., Tesluk, P., Locke, E. and Bartol, K. (2007) "A multilevel investigation of the motivational mechanisms underlying knowledge sharing and performance", Organization Science, 18(1), 71-88.

[51] Reich, B., Gemino, A. and Sauer, C. (2012) "Knowledge management and project-based knowledge in IT projects: a model and preliminary empirical results", International Journal of Project Management, 30(6), 663-674.

[52] Reich, B., Gemino, A. and Sauer, C. (2013) "How knowledge management impacts performance in projects: An empirical study", International Journal of Project Management, 32(4), 590-602

[53] Richards, C., Thompson, C. W., and Graham, N. (2014). Beyond designing for motivation: the importance of context in gamification. InProceedings of the first ACM SIGCHI annual symposium on Computer-human interaction in play 217-226.

[54] Rodrigues, L. F., Costa, C. J., and Oliveira, A. (2013). How to develop financial applications with game features in e-banking? In Proceedings of the 2013 International Conference on Information Systems and Design of Communication 124-134. ACM.

[55] Roth, S., Schneckenberg, D. and Tsai, C.-W. (2015) "The Ludic Drive as Innovation Driver: Introduction to the Gamification of Innovation", Creativity and Innovation Management, 24, 300-306

[56] Seaborn, K., and Fels, D. I. (2015) "Gamification in theory and action: A survey", International Journal of Human-Computer Studies, 74, 14-31.

[57] Shields, P., and Rangarajan, N. (2013) "A Playbook for research methods: integrating conceptual frameworks and project management”, New Forums press

[58] Vasilescu, B., Serebrenik, A., Devanbu, P., and Filkov, V. (2014). "How social Q and A sites are changing knowledge sharing in open source software communities." Proceedings of the 17th ACM conference on Computer supported cooperative work and social computing, 342-354

[59] Watson, T. (1994). "Managing, crafting and researching: words, skill and imagination in shaping management research", British Journal of Management, 80 